\title{
NILAI PROFETIK DAN PENDIDIKAN ISLAM HUMANISTIK DALAM NOVEL 99 CAHAYA DI LANGIT EROPA KARYA HANUM SALSABIELADANRANGGAALMAHENDRA:KAJIANSEMIOTIK DAN RELEVANSINYA DALAM PEMBELAJARAN SASTRA INDONESIA DI SMA
}

\author{
Ferdiansyah \\ Universitas Muhammadiyah Surakarta \\ ferdiansyahbima@gmail.com
}

\begin{abstract}
Abstrak
Tujuan penelitian ini adalah (1) mendeskripsikan latar sosial budaya pengarang Hanum Salsabiela dan Rangga Almahendra, (2) mendeskripsikan struktur dalam novel 99 Cahaya di Langit Eropakarya Hanum Salsabiela dan Rangga Almahendra, (3) mendeskripsikan nilai profetik dan pendidikan Islam humanistik dalam novel 99 Cahaya di Langit Eropakarya Hanum Salsabiela dan Rangga Almahendra (4) mendeskripsikan relevansi nilai profetik dan pendidikan Islam humanistik dengan relevansi dalam pembelajaran sastra Indonesia di SMA. Teknik pengumpulan data dilakukan dengan teknik pustaka, teknik simak dan teknik catat. Teknik analisis data menggunakan metode dialektik, dengan model semiotik dan pembacaan heuristik dan hermeneutik. Hasil penelitian ini adalah nilai profetik dan pendidikan Islam humanistik menghasilkan (1) pendidikan dan humanum, (b) pendidikan dan humanitas, (3) pendidikan dan humaniora, dan misi profetik nya(1) Amar ma'ruf (humanisasi), (2) Nahi munkar (liberasi) (3) Tu'minuna billah (transendensi). Relevansinya nilai profetik dan pendidikan Islam humanistik dengan pembelajaran sastra Indonesia di SMA dapat dilihat dari standar kompetensi yang telah ditetapkan berupa sikap (attitude) sama dengan pendidikan dan humanitas, keterampilan (skill) sama dengan pendidikan dan humaniora, dan pengetahuan (knowledge) sama dengan pendidikan humanum.
\end{abstract}

Kata Kunci: Nilai profetik, pendidikan Islam humanistik, novel 99 cahaya di langit Eropa, kajian semiotik, relevansi pembelajaran sastra Indonesia di SMA.

\begin{abstract}
The purpose of this study is (1) to describe the background of the sociocultural authors Hanum Salsabiela and Rangga Almahendra, (2) describe the structure of the novel 99 Cahaya di Langit Eropa works Hanum Salsabiela and Rangga Almahendra, (3) describe the prophetic value and Islamic education humanistic novel 99 Cahaya di Langit Eropa works Hanum Salsabiela and Rangga Almahendra (4) describe the relevance of Islamic prophetic value and humanistic education with relevance in learning Indonesian literature at the high school. Data collected by using libraries, refer to the engineering and technical notes. Data were analyzed using the dialectical method, with the semiotic models and heuristic and hermeneutic reading. The results of this study are prophetic value and humanistic Islamic education provides: (1) education and humanum, (b) education and humanities, (3) education and humanities, and his
\end{abstract}


prophetic mission (1) Amar ma'ruf (humanization), (2) nahimunkar(liberation) (3) Tu'minuna billah (transcendence). Relevance prophetic value and Islamic education humanistic with the teaching of Indonesian literature in high school can be seen from the competency standards that have been established in the form of an attitude (attitude) is the same with education and humanities, skills (skills) together with education and humanities, and knowledge (knowledge) is the same with education humanum.

Keywords: Value prophetic, humanistic Islamic education, 99 novel light the skies of Europe, semiotic studies, the relevance of learning Indonesian literature at the high school.

\section{Pendahuluan}

Kehadiran karya sastra di tengah masyarakat tidak lahir dari kekosongan budaya (Teeuw, 1984, p. 11), melainkan ada unsur kesinambungan tradisi sepanjang yang dijalani pengarang.Faktor sosio-budaya, ideologi dan pembaca sangat menentukan bagaimana sastra itu diterima masyarakat.Berdasarkan hal tersebut, kehadiran sebuah karya pada masa kurun tertentu merupakan hasil refleksi pengarang terhadap realitas yang dijalaninya.Sebagaimana dikemukakan Hudson (dalam Al Maruf, 2010, p. 1) bahwa karya sastra melukiskan corak, cita-cita, aspirasi dan prilaku masyarakat. Dengan refleksi, kontemplasi dan seluruh imajinasi pengarang akan menghasilkan karya sastra dalam berbagai bentuk dan jenis berupa prosa, puisi, cerpen, drama.

Karya sastra merupakan salah satu dari sejumlah besar hasil peradaban manusia. Karya sastra menjadi satu aktivitas imajinatif dan kreativitas bagi kehidupan manusia dalam memberdayakan potensinya.Karenanya, karya sastra memberi keindahan pada pembacanya, di samping sebagai media komunikasi antara pengarang dengan pembacanya (Ratna, 2013, p. 107).Karya sastra merupakan sebuah sistem yang mempunyai konvensi-konvensi tersendiri. Dari jenis (genre) sastra dan ragamnya; jenis sastra dapat berupa prosa dan puisi, prosa mempunyai ragam yakni cerpen, roman (novel).Jenis puisi dapat berupa puisi lirik, syair, pantun, balada dan sebagainya. Dengan demikian, novel merupaka salah satu genre karya sastra yang berbentuk prosa.

Novel 99 Cahaya di Langit Eropa karya Hanum Salsabiela Rais dan Rangga Almahendra(selanjut disingkat $C d L E$ ) merupakan novel inspiratif, novel yang penuh nilai profetik dan pendidikan Islam humanistik. Novel 99 CdLE dapat menjadi pencerah bagi pembaca dalam memandang pendidikan bertoleransi dan menyikapi perbedaan agama. Novel ini membawa pesan yang sangat kompleks dalam kehidupan sosial, budaya dan dunia pendidikan, dari pendidikan keluarga, pendidikan formal sehingga menjadi seorang pendidik yang baik.

Novel 99 CdLE karya Hanum Salsabiela Rais dan Rangga Almahendra adalah perjalanan spritual di Eropa, tetapi juga novel sejarah Islam di Eropa. Berbeda dengan banyak karya lain tentang pertemuan dan perbenturan Islam di Eropa, dengan gaya bertutur personalnya. Novel ini layak di baca bagi pendidik, orang tua, tokoh agama, dan siapa saja yang mau menimba kearifan. Oleh karena itu, novel ini penuh dengan nuansa dan gemuruh perjalanan sejarah peradaban Islam Eropa, baik pada masa silam maupun pada masa sekarang.

Hanum Salsabiela Rais dan Rangga Almahendra merupakan penulis yang kreatif. Banyak karya-karya yang dihasilkannya, novel 99 Cahaya di Langit Eropa merupakan 
novel keduanya dan sudah di transformasikan menjadi film. Penulis memulai petualangan di Eropa selama tinggal di Austria bersama suaminya Rangga Almahendra dan bekerja untuk proyek video Podcast Executive di WU Vienna selama 2 tahun. Ia juga juga tercatat sebagai koresponden detik.com untuk kawasan Eropa dan sekitarnya. Tahun 2010, penulis menerbitkan buku pertamanya, Menapak Jejak Amien Rais: Persembahan Seorang Putri untuk Ayah Tercinta. Sebuah novel biografi tentang kepemimpinan, keluarga, dan mutiara hidup. Sejak umur 17 tahun, penulis sudah terjun dalam dunia broadcasting dan jurnalistik. Ia mengawali kariernya sebagai pembawa acara lepas di stasiun TVRI Yogyakarta dan jogja TV. Pada tahun 2006, Penulis mencoba meniti karier di Jakarta dan bekerja sebagai reporter di TRANS TV.Di stasiun TV ini pula penulis membawakan program berita harian Reportase.

Masalah yang menarik dalam Novel 99 CdLE adalah ketika Islam atau muslim berhadapan dengan realitas kian sulit di Eropa. Padahal Islam pernah memberikan kontribusi besar dalam kebangkitan Islam di Eropa menuju dunia moderen, kontribusi yang kini juga tetap di berikan malalui pribadi-pribadi muslim yang berkiprah dalam bidang keilmuan, seperti Marion Latimer dan banyak lagi kaum muslimin yang bergerak dalam ketenagakerjaan dan ekonomi Eropa. Tidak ragu lagi, novel ini memberikan kontribusi besar untuk memahami dinamika Islam pada peradaban masyarakat Eropa, sekaligus ke arah pemahaman lebih baik tentang lingkungan hidup masyarakat muslim dalam diaspora Eropa.

Menurut Habibie (dalam Hanum dan Rangga 2013, p. ix ) novel 99 CdLE yang ditulis berdasarkan pengamatan hidup di Eropa selama tiga tahun. Pengarang kemudian menyimpulkan bahwa kondisi umat Islam saat ini sudah semakin jauh dari akar yang membuat peradaban Islam terpuruk, karena kondisi umat kini yang menyalahartikan “ jihad” sebagai perjuangan dengan pedang, bukan dengan perantaraan kalam (pengetahuan dan teknologi ).

Pengamatan pengarang, sekali lagi menunjukan kepada kita bahwa kebudayaan dan teknologi selalu berjalan berdampingan, saling mengisi, menentukan masa depan suatu bangsa. Jika kebudayaan suatu bangsa mati, mati pula teknologi bangsa itu.Di luar meredupnya peradaban Islam, lihat saja persamaan dengan kepunahan suku Indian Maya di Amerika Latin, bersamaan dengan punahnya teknologi suku tersebut. Begitu pula jika kebudayaan dan teknologi suatu bangsa dikekang, bangsa itu tidak akan tumbuh. Sebaliknya jika keduanya diberikan kesempatan mekar, maka masa depan bangsa itu akan mekar dan berkembang pesat.

Menurut Baswedan (dalam Hanum dan Rangga, 2013,p.x) lewat kisah-kisah sederhana dan menarik, pengarang membukakan mata tentang pernak-pernik kehidupan Islam di Eropa dan mengajak untuk flash back melihat masa lalu. Pengarang mampu merangkai kepingan mosaik tentang kebesaran Islam di Eropa beberapa abad lalu.Lebih jauh lagi, melihat nilainilai Islam dalam kehidupan Eropa. Islam dan Eropa sering ditempatkan dalam stigma " berhadapan " sudah saatnya ditempatkan dalam kerangka stigma "saling menguatkan"

Menurut Hamka (dalam Susanto, 2009, p. 106) pendidikan Islam adalah pendidikan yang tidak hanya terfokus memperoleh kehidupan yang layak, lebih dari itu ilmu harus mengenalkan dengan Tuhannya, memperluas akhlaknya, dan senantiasa berupaya mencari keridhaan Allah. Menurut Baharuddin dan Makin pendidikan Islam humanistik adalah pendidikan yang memandang manusia sebagai manusia, yakni makhluk ciptaan Allah dengan fitrah-fitrah tertentu untuk dikembangkan secara maksimal dan optimal. Menurut Nurcholish Majid misi profetik sama dengan tugas suci Nabi yang utama, yaitu menegakkan keadilan. Menurut Kuntowijoyo (2006, p. 91) misi profetik mengandung 3 unsur yakni menyeru kepada yang ma'ruf, mencegah dari yang munkar, dan beriman kepada Allah. 
Berdasarkan latar belakang di atas, maka dilakukan penelitian tentang nilai profetik dan pendidikan Islam humanistik dalam novel 99 Cahaya Di Langit Eropa Karya Hanum Salsabiela dan Rangga Almahendra dengan kajian semiotik, tentang relevansinya dalam pembelajaran bahasa dan sastra Indonesia di SMA"

\section{Metode Penelitian}

Jenis penelitian dalam tesis ini adalah deskriptif kualitatif.Menurut Sutopo (dalam Ma'ruf, 2010, p. 32) penelitian kualitatif deskriptif bertujuan untuk mengungkapkan berbagai informasi kualitatif dengan pendeskripsian yang teliti, cermat, sifat-sifat suatu hal, keadaan, fenomena dan tidak terbatas pada pengumpulan data melainkan meliputi analisis dan interpretasi data. Objek penelitian ini adalah nilai profetik dan pendidikan Islam humanistik dalam novel 99 Cahaya di Langit Eropa karya Hanum Salsabiela dan Rangga Almahendra.

Data penelitian ini berupa kata, kalimat, dan paragraf dalam novel 99 Cahaya di Langit Eropakarya Hanum Salsabiela dan Rangga Almahendra.Sumber data primer dalam penelitian ini adalah novel 99 Cahaya di Langit Eropa.Data sekunder dalam penelitian ini adalah Putri (2012) tesis dengan judul "Konsep Pendidikan Humanistik Ki Hajar Dewantara dalam Pandangan Islam". Rahmahana (2008) dalam jurnalnya yang berjudul "Psikologi Humanistik dan Aplikasinya dalam Pendidikan". Fahruddin (2008) dalam Tesisnya "Konsep Pendidikan Humanis dalam Perspektif Al-Quran". Teknik pengumpulan data yakni teknik pustaka, teknik simak, dan teknik catat. Teknik validitas data yang digunakan adalah trianggulasi teoretis.

\section{Hasil Penelitian dan Pembahasan}

\subsection{Analisis Nilai Profetik dan Pendidikan Islam Humanistik dalam Novel 99 Cahaya di Langit Eropa Karya Hanum Salsabiela dan Rangga Almahendra}

Misi profetik yang terpenting adalah dapat melayani umat, menjadi bagian dari inteligensi kolektif,mampu mengarahkan umat ke arah evolusi sosial secara rasional. Dari penjelasan di atas, dapat disimpulkan bahwa misi profetik adalah suatu cita-cita profetik yang diturunkan dari misi historis Islam sebagaimana terkandung dalam Qs. 4 [Ali Imran]: 110, "Kamu (umat Islam) adalah umat terbaik yang dilahirkan untuk manusia, (karena kamu) (menyuruh berbuat) yang ma'ruf dan mencegah dari yang mungkar, dan beriman kepada Allah...'. dari ayat ini dapat terdapat perintah kepada manusia untuk melaksanakan Amar ma'ruf, nahi munkar, dan tu'minunabillah, tiga muatan inilah yang mengkarakterisasikan ilmu sosial profetik menjadi landasan misi profetik.

\subsubsection{Amar ma'ruf (Humanisasi)}

Amar ma'ruf (Humanisasi) adalah proses memanusiakan manusia, memperlakukan manusia sesuai dengan fitrahnya melalui spirit atau semangat untuk mengajar dan belajar yang harus dilakukan oleh pendidik maupun peserta didik. Hal ini akan dibahas sebagai berikut.

Hanum bersama teman-teman Islamnya di Austria merupakan sumberdaya manusia yang kreatif.Mereka mempunyai semangat yang tinggi untuk belajar mengajar. Walaupun mereka diperhadapkan dengan kesibukan, seperti berdagang dan berbisnis, mereka tetap menyempatkan diri untuk membuka forum untuk bertukar pikiran. Tidak hanya itu, mereka juga saling menggurui untuk sama-sama belajar membaca Al-Qur,an. Hal ini dapat dilihat dalam kutipan berikut. 
"Kami di sini sering bertukar pikiran. Tentang kehidupan dan cara menyiasati hidup di Austria," ucap Fatma menjawab keingintahuanku tentang apa kegiatan mereka di rumah Fatma. Agaknya aku mulai paham, kegiatan mereka ini seperti pengajian atau arisan di Indonesia. "Kau sudah bisa membaca Al-Qur'an, kan?" Tiba-tiba Ezra yang tambun menanyaiku.Aku menggangguk. “ Oh, kalau belum, kita disini juga belajar memabaca Al-Qur'an. Aku juga baru belajar.Mereka ini bergantian menjadi guruku,' terang Ezra menunjuk Latife, Oznur, dan Fatma sebagai mentornya.(hlm. 89).

Dari kutipan tersebut dapat diketahui bahwa Hanum bersama teman-teman muslimnya di Austria sangat antusias untuk belajar. Mereka tidak hanya belajar ilmu sosial, tetapi mereka juga punya kemauan dan gigih untuk sama-sama belajar membaca Al-Qur'an. Ini adalah cermin dari misi profetik atau kenabian. Seperti di dalam firman Allah Swt di dalam surat Al-Mujadilah [29:11]. "Sesungguhnya Allah akan mengangkat (derajat) orangorang yang beriman diantaramu dan orang-orang yang diberi ilmu beberapa derajat. Dan Allah maha teliti apa yang kamu kerjakan. (Q.S. Al-Mujadilah). Lalu kemudian ayat di atas dikuatkan oleh hadist yang diriwayatkan dari Utsman bin 'Affan r.a., sesungguhnya Rasulullah saw. Bersabda, "Sebaik-baiknya kamu adalah orangyang belajar al-Quran dan mengajarkannya."(HR. Tirmidzi..., hadits no. 2907).

Hanum dalam menuntut ilmu tidak hanya belajar di kampus atau di lembaga formal, tetapi dia juga banyak belajar kepada Fatma tentang bagaimana arti kesabaran dan menahan emosi sesuai dengan syariat Islam.Hal ini dapat dilihat dalam kutipan berikut.

“Bagaimana kau bisa tak marah sedikit pun, Fatma?” tanyaku lagi. " Tentu saja aku tersinggung, Hanum. Dulu aku juga jadi emosi jika mendengar hal yang tak cocok di negeri ini.Apalagi masalah etnis dan agama. Tapi seperti kau dan dinginnya hawa di Eropa ini, suhu tubuhmu akan menyesuaikan. Kau perlu penyesuaian, Hanum. Hanya satu yang harus kita ingat. Misi kita adalah menjadi agen Islam yang damai, teduh, indah, yang membawa keberkahan di komunitas nonmuslim. Dan itu tidak akan pernah mudah."(hlm. 49).

“Tapi, bukankah itu menunjukkan kita begitu lemah dan terinjak-injak?” sanggahku. Fatma terdiam.Dia tersenyum lembut, lalu mengambil napas dalam-dalam.

"Suatu saat kau akan banyak belajar bagaimana bersikap di negeri tempat kau menjadi minoritas. Tetapai menurut pengalamanku selama ini, aku tak harus mengumbar nafsu dan emosiku jika ada hal yang tak berkenan di hatiku."(hlm. 49).

Dari kutipan di atas dapat dilihat bahwa Hanum mengagumi kemampuan Fatma dalam menjalani dan menyikapi dinamika kehidupannya yang terjadi di lingkungan sosial di Eropa. Hanum merasa terkagum karena Fatma begitu indah dalam menyikapi masalah yang berkaitan dengan etnis dan agama. Artinya, ketika ada orang nonmuslim yang menceritakan tentang kejelekan Islam, Fatma tidak membalas dengan perkataan kasar atau sikap antipati. Akan tetapi, dia cukup membalas dengan senyum saja. Misi Fatma adalah menjadi agen muslim yang damai, teduh, indah yang membawa keberkahan di komunitas nonmuslim. Di situlah Hanum menyadari dan banyak belajar kepada Fatma tentang cara menyikapi problem kehidupan di masyarakat yang mayoritas nonmuslim, karena Fatma sebagai seorang muslimah yang menjujung tinggi dan mengharap janji dari Allah Swt. Seperti firman Allah Swt di dalam surat Al-Hujrat [26:13]. "Sesungguhnya orang yang paling mulia diantara 
kamu disisi Allah Swt adalah orang yang paling bertakwa diantara kamu" [Q.S Al-Hujrat]. Dan ayat di atas diikuti oleh hadist baginda nabi Muhammad Swt yang diriwayatkan dari " Iyadh bin Himar r.a. menceritakan, " Akuberkata (kepada Nabi saw.), "Wahai Nabi Allah! Seseorang dari kaumku telah mencaci maki aku, padahal kedudukannya lebih rendah daripada aku, bolehkah membalasnya?" Beliau menjawab, "Dua orang yang saling mencaci maki adalah seperti dua syetan yang saling menjelekkan dan saling mendustakan." (HR. Ibnu Hibban, hadist no. 6044).

\subsubsection{Nahi munkar (liberasi)}

Nahi munkar (liberasi) adalah pembebasan manusia dari segala penindasan, kebodohan, kemiskinan.Sasaran dari liberasi yakni sistem pengetahuan, sistem sosial, sistem ekonomi, dan sistem politik.Akan tetapi, yang dibahas dalam penelitian ini hanya dikhususkan pada sistem pengetahuan, dan sistem sosial. Hal ini akan dibahas sebagai berikut

Fatma menyadari bahwa sangat penting manusia berpengetahuan agar tidak mengalami penindasan dan kebodohan. Langkah nyata yang dilakukan Fatma adalah dengan mendesain sistem pengetahuan yakni membuka forum diskusi antarmuslim di rumahnya untuk sama- sama belajar dengan teman-teman seiman di Austria. Hal ini dapat dilihat dalam kutipan berikut.

"Hanum, hari ini aku dan beberapa kawan akan mengadakan pertemuan.Biasalah ibu-ibu saling berbincang-bincang.Kau akan kuperkenalkan kepada mereka, Hanum,", ucap Fatma bersemangat." Hanum, ini Latife, Ezra, dan Oznur," ucap Fatma memperkenalkan para model pemakai batikku.” (hlm. 87)

"Kami di sini sering bertukar pikiran. Tentang kehidupan dan cara menyiasati hidup di Austria, “ ucap Fatma menjawab keingintahuanku tentang apa kegiatan mereka di rumah Fatma. Agaknya aku mulai paham, kegiatan mereka ini seperti pengajian atau arisan di Indonesia." (hlm. 89)

"Ini semua inisiatif Fatma.Awalnya kita hanya bertemu untuk bersanda gurau tanpa tujuan.Bicara tentang anak, masalah pribadi, hingga curhat keluh kesah sebagai warga pendatang di Austria, kurang bergunalah," kata Oznur membuka perbincangan." LaluFatma meluncurkan ide untuk mengkaji Al-Qur'an bersama. Kebetulan aku, Latife, dan Fatma sama-sama datang dari Istanbul.Lalu karena aku dan Fatma kurang bisa berbahasa Jerman, kami meminta Latife mengajari kami.” (hlm. 91)

Dari kutipan di atas dapat dilihat bahwa pertemuan Fatma, Hanum, dan teman-teman muslim di rumah Fatma merupakan kegiatan yang begitu mulia. Mereka tidak hanya belajar mengenai cara kehidupan yang baik di Austria. Akan tetapi, mereka juga belajar mengkaji dan membaca Al-Qur'an.Inilah salah satu wilayah garapan liberasi yaitu pembebasan orang dari kebodohan. Seperti dalam firman Allah Swt di dalam surat (Al-An'am: 91). "Katakanlah, 'Allah, kemudian (sesudah menyampaikan Al-Qur'an kepada mereka), biarkanlah mereka bermain-main dengan kesesatannya." (Q.S. Al-An'am). Dan surat di atas diperkuat olehhadist riwayat dari Abu Hurairah r.a. berkata, "Aku mendengar Abul Qosim (Rasulullah) saw bersabda, 'Orang yang terbaik di antara kalian adalah yang terbaik akhlaknya, jika mereka memahami agama' (HR. Ibnu Hibban). 
Selain itu, tokoh Marion mengajak Hanum untuk mengeksplorasi museum Louvre. Selama berada dalam museum, Hanum intens bertanya kepada Marion. Pengetahuan Marion membuat Hanum semangat untuk menjelajahi benda-benda yang ada dalam museum tersebut.Hal ini dapat dilihat dalam kutipan berikut.

"Marion, ini apa? Seperti bola dunia," aku memberanikan diri bertanya padanya, sambil menunjuk sebuah benda aneh berbentuk bola emas dengan tulisan dan angkaangka yang tak kumengerti. " Hampir benar, tapi ini lebih daripada itu. Ini bola langit.Lebih tepatnya peta antariksa ilmu falak yang dikembangkan astronom Islam abad ke-12."(hlm. 151).

“Tulisan apa itu?”Tanyaku diliputi rasa penasaran. "Al-ilmu murrun fil bidayah, wa ahla minal'asalifin-nihayah.Kira-kira begitu, " ucap Marion dengan bahasa Arab yang sangat lancar.Aku baru tersadar dia bekerja sebagai peneliti di Arab World Institute Paris yang mensyaratkan keahlian bahasa Arab. "Al-Qur'an atau Hadist? "Tanyaku memberinya pilihan.Ungkapan Arab tadi tak pernah kudengar sebelumnya.” (hlm. 153)

"Sepertinya itu tulisan Kufic.Seni kaligrafi Arab kuno.Tak terbaca dengan pengetahuan biasa.Sekilas hanya seperti coretan Arab yang tak ada artinya.Tapi ini sebuah misi dakwah yang luar biasa.Para kalifah Islam senang mengirim cendera mata dengan pesan puitis dengan dekorasi Kufic seperti ini kepada raja-raja Eropa yang kebanyakan menganut Katolik Roma." (hlm. 155)

Dari kutipan di atas dapat dilihat bahwa Marion mampu menjelaskan semua bendabenda yang bertulisakan kaligrafi Arab yang ada dalam museum Louvra di Paris. Hanum mengagumi potensi Marion yang bisa menginterpretasi kaligrafi Arab tersebut, yang sebelumnya Hanum tidak pernah mendengarnya. Akan tetapi, Hanum menyadari bahwa Marion adalah seorang yang bekerja sebagai peneliti di Arab World Institute Paris yang mensyaratkan harus bisa bahasa Arab.

\subsubsection{Tu'minuna billah (transendensi)}

Tu'minuna billah (transendensi) mempunyai makna teologis, yakni ketuhanan, maksudnya beriman kepada Allah Swt. Transendensi bertujuan menambahkan dimensi transendental dengan cara membersihkan diri dari arus hedonisme, materialisme, dan budaya yang dekaden. Singkatnya, menghendaki manusia untuk mengakui otoritas mutlak Allah Swt.

Dalam novel $99 C d L E$ pengarang mencoba menggambarkan tentang bagaimana cara mengajak umat manusia untuk beriman kepada Allah Swt. Sesuai dengan konsep transendensi yakni menghendaki manusia untuk mengakui otoritas mutlak Allah Swt. Hal ini dapat dilihat dalam kutipan berikut.

"Mm... ya.ini pertama kalinya saya ke sini. Masjid paling besar, ya..Tapi mengapa harus dekat dengan semua itu?" tanganku kuhamparkan. Aku bingung mencari perbandingan kata yang lebih halus daripada "tempat yang 'menggoda syahwat". Rangga yang berdiri tepat di sampingku langsung mencubit punggungku.Aku tahu 
pertanyaan ku berlebihan, apalagi kami baru saja berkenalan.Tapi hanya pertanyaan itu yang tiba-tiba tebersit di otakku.

"Itulah..itu penerimaan orang luar seperti anda yang melihat ke dalam. Namun untuk saya, orang dalam yang melihat keluar, masjid yang berada didekat Danube justru merupakan berkah," ucap Imam Hashim lembut. Dia membuatku bertanya-tanya. (hlm. 116).

"Mari masuk ke kantor saya. Inilah berkah itu, Imam Hashim mengeluarkan catatan dari balik lemari. "Orang-orang yang baru saja masuk Islam? Mualaf?" sahut Rangga terkesiap. "Ini adalah daftar nama orang yang masuk Islam. Di antara mereka adalah yang tadinya senang berjemur dan menikmati suasana musim panas di tepi Danube.

"Hidayah turun tak pernah tahu di mana dan bagaimana.Tidak semua orang yang mengucap syahadat mendapatkan saat di sungai Danube. Banyak cara dan jalan ketika hidayah itu muncul, lalu meresap ke dalam hati daan jiwa (hlm. 117)

Dari kutipan di atas dapat dilihat bahwa tokoh Imam Hashim mencoba menjelaskan sekaligus menjawab pertanyaan Hanum dan Rangga tentang berkah eksistensi masjid yang berdiri di tepi Sungai Danube. Berkah yang dimaksud Imam Hashim adalah banyaknya orang nonmuslim yang masuk Islam (mualaf) dengan adanya masjid tersebut, diantaranya orang-orang yang senang berjemur di tepi Sungai Danube.Lalu kemudian, Imam Hashim mengeluarkan catatan nama-nama orang nonmuslim yang masuk Islam (mualaf).Setelah itu, Imam Hashim sedikit menceramahi Hanum dan Rangga mengenai konsep Islam.Islam adalah agama yang benar dan lurus untuk jalan menuju surga.Itu adalah keyakinan kita semua. Lalu, bagaimana Islam memandang orang-orang nonmuslim?Pada dasarnya semua orang mendapatkan hidayah itu. Pada satu titik dalam kehidupannya, setiap manusia di dunia ini pada dasarnya pernah berpikir tentang siapakah dirinya, mengapa dan untuk apa dia hidup, dan adakah kekuatan di atas kekuatan hidupnya. Hanya saja ada yang kemudian mencari dan menelisik, ada pula yang membuangnya jauh-jauh atau melupakannya.Yang mencari pun ada yang caranya salah dan keliru. Tetapi pada akhirnya, semua kembali ke individu itu sendiri.kemudian orang sudah mempunyai pendirian, kita tidak berhak mengusiknya. Seperti dalam ( Qs. Al Jumu'ah [62]: 2 ). "Dialah yang mengutus kepada kaum yang buta huruf seorang Rasul di antara mereka, yang membacakan ayat-ayat-Nya kepada mereka, mensucikan mereka dan mengajarkan kepada mereka Kitab dan Hikmah (as Sunnah). Dan sesungguhnya mereka sebelumnya benar-benar berada dalam kesesatan yang nyata."

Setiap manusia pasti menginginkan yang lebih baik dalam kehidupan di dunia ini, terlebih lagi masalah kehidupan spritual.Artinya, setiap insan pasti memiliki kemampuan untuk bisa mendekatkan diri kepada Allah swt.Namun, semua itu tidak mudah untuk mengimplementasikannya, harus butuh usaha keras untuk memaksimalkan keyakinan dalam dirinya.Dan inilah misi yang mau dilakukan oleh tokoh Fatma kepada generasi-generasi penerusnya nanti.Yang sesuai dengan konsep transendensi yakni menghendaki manusia untuk mengakui otoritas mutlak Allah Swt. Hal ini dapat dilihat dalam kutipan berikut.

"Sekarang ini anak-anak makin melupakan sejarah agama. Aku ingin suatu saat nanti, dari awal kedatangan di dunia ini seluruh anak muslim tahu, tiada kebanggaan yang berarti kecuali menjadi muslim. Aku ingin mereka lahir sebagai muslim karena mereka memahami, meresapi, mengenal, menyentuh, merasakan, dan mencintai Islam, bukan karena paksaan orang lain. Dan aku ingin mereka tahu bahwa dalam setiap 
waktu, dalam masa depan mereka, mereka akan menemui orang-orang yang berbeda dalam hal kepercayaan, bahasa, dan bangsa. Aku akan mengajarkan kepada mereka bahwa perbedaan terjadi bukan karena Tuhan tidak bisa menjadikan kita tercipta sama. Menciptakan manusia homogen itu bukan perkara yang sulit untuk-Nya. Itu semua terjadi justru karena Tuhan mahatahu, jika kita semua sama, tidak ada lagi keindahan hidup bagi manusia. Jadi, nikmatilah perbedaan itu, " ujar Fatma begitu mantap. (hlm. 368)

Dari kutipan di atas dapat dilihat bahwa apa yang disampaikan oleh tokoh Fatma adalah sesuatu yang sangat substansi, dengan menekankan kepada kita semua untuk bisa mendekatkan diri kepada Allah swt. Selain itu, Fatma juga menginginkan agar generasi yang akan datang bisa menyikapi, meresapi, dan mengenal Islam dengan bijaksana tanpa ada paksaan atau intervensi dari orang lain. Fatma juga ingin mengajarkan kepada mereka bahwa perbedaan terjadi bukan karena Tuhan tidak bisa menjadikan kita tercipta sama, tetapi, justru karena Tuhan Mahatahu. Jika kita semua sama, tidak ada lagi keindahan hidup bagi manusia. Artinya,nikmatilah perbedaan itu. Seperti dalam suratAl-Kafirun ayat ke-6. "Bagi kalian agama kalian dan bagiku agamaku"

\subsection{Relevansi Nilai Profetik dan Pendidikan Islam Humanistik dalam Novel 99 Cahaya di Langit Eropa Karya Hanum Salsabiela dan Rangga Almahendra Dengan Bahan Ajar Sastra Indonesia Di SMA}

Nilai profetik dan pendidikan Islam humanistik menghasilkan sistem pendidikan baru yakni sistem pendidikan syumuliyyah Islam. Sistem pendidikan syumuliyyah Islam adalah sistem pendidikan yang di dalamnya terdapat nilai-nilai pendidikan berupa pendidikan humanum, pendidikan humanitas, pendidikan humaniora, dan amar maruf (humanisasi), nahi munkar (liberasi) dan tu'minuna billah (transendensi).

Berdasarkan analisis yang telah dilakukan peneliti, relevansi antara sistem pendidikan sumuliyyah Islam dengan bahan ajar sastra di SMA adalah sebagai berikut.

a. Mengembangkan keseimbangan antara pengembangan sikap spiritual dan sosial, rasa ingin tahu, kreativitas, kerja sama dengan kemampuan intelektual dan psikomotorik;

b. Sekolah merupakan bagian dari masyarakat yang memberikan pengalaman belajar terencana dimana peserta didik menerapkan apa yang dipelajari di sekolah ke masyarakat dan memanfaatkan masyarakat sebagai sumber belajar;

c. Mengembangkan sikap, pengetahuan, dan keterampilan serta menerapkannya dalam berbagai situasi di sekolah dan masyarakat;

d. Memberi waktu yang cukup leluasa untuk mengembangkan berbagai sikap, pengetahuan, dan keterampilan;

e. Kompetensi dinyatakan dalam bentuk kompetensi inti kelas yang dirinci lebih lanjut dalam kompetensi dasar mata pelajaran;

f. Kompetensi inti kelas menjadi unsur pengorganisasi (organizing elements) kompetensi dasar, dimana semua kompetensi dasar dan proses pembelajaran dikembangkan untuk mencapai kompetensi yang dinyatakan dalam kompetensi inti;

g. Kompetensi dasar dikembangkan berdasarkan pada prinsip akumulatif, saling memperkuat (reinforced) dan memperkaya (enriched) antarmatapelajaran dan jenjang pendidikan (organisasi horizontal dan vertikal).

Berdasarkan pemaparan beberapa poin di atas bahwa sistem pendidikan sumuliyyah Islam dengan bahan ajar di SMA, terdapat relevansi karena sistem pendidikan sumuliyyah Islam 
juga mengandung unsur-unsur pengembangan sikap spiritual dan sosial, menjadikan sekolah sebagai tempat belajar dan masyarakat sebagai sumber pembelajaran, mengembangkan sikap, pengetahuan, keterampilan, memberi waktu yang cukup leluasa untuk mengembangkan berbagai sikap, pengetahuan, dan keterampilan yang akan bermanfaat bagi siswa.

Dalam orientasi pengembangan bahan ajar sastra adalah berupa sikap (attitude), keterampilan (skill), dan pengetahuan (knowledge).Peneliti meyakini bahwa sistem pendidikan sumuliyyah Islam menjadi relevan karena sistem pendidikan sumuliyyah Islam mencakup pendidikan dan humanitas yang mengembangkan aspek sikap.Pendidikan humanitas terdiri atas sikap penuh penghormatan, saling percaya, peduli dan penuh perhatian, ikhlas dan saling percaya, dan pendidikan penuh perhatian dan penghormatan. Hal ini dapat dilihat dalam beberapa kutipan berikut.

a. Penuh Penghormatan

Pendidikan Islam humanistik salah satu unsurnya adalah pendidikan dan humanitas. Hal ini dapat dilihat dari beberapa kisah, melalui hubungan tokoh Hanum dan Marion yakni sesampai Hanum di Paris, Hanum langsung di jemput oleh Marion. Selain itu, Hanum juga diajak oleh Marion untuk jalan-jalan mengelilingi kota Paris. Hal ini dapat dilihat dalam kutipan berikut.

“Hanum Indonesia!'Sebuah suara mengagetkanku dari belakang.Kata-kata itu langsung membuat kami menoleh.Itulah kali pertama kami kelihat Marion Latimer. Perempuan yang selama ini hanya kukenal lewat e-mail selama kurang dari sebulan.

"Aku ingin tahu, apa yang membuatmu tertarik pada Islam.mungkin aku bisa belajar banyak darimu," ucapku setengah bercanda. Marion hanya tersenyum simpul.Kemudian aku dan Rangga berjalan mengikutinya.

"Jangan khawatir Hanum, aku akan mengajakmu jalan-jalan mengenal sisi lain kota Paris, yang pasti akan membuatmu makin jatuh cinta dengan agamamu. Aku mengenal Islam justru dari kota ini. Aku memeluk Islam karena..Paris. Ayo, kita jalan menuju mobilku," ajak Marion kepada kami." (hlm. 132)

Dari kutipan di atas dapat dilihat bahwa Hanum di jemput oleh Marion setelah sampai di kota Paris. Dan situlah Hanum baru pertama kali melihat langsung dengan Marion yang sebelumnya, dia hanya berkenalan lewat e-mail. Namun, disisi lain Hanum juga penasaran dengan latar belakang Marion yang membuat dia tertarik untuk masuk Islam. Lalu kemudian, Marion berkelakar bahwa dia ingin mengajak Hanum untuk jalan-jalan mengenal sisi lain kota Paris, karena di Paris lah dia pertama kali memeluk Islam.

b. Saling Percaya

Dalam novel $99 C d L E$ terdapat nilai kepercayaan yang tinggi antara tokoh Fatma dengan teman-teman muslimnya di Austria. Salah satu saling percayanya adalah Fatma menitipkan anaknya kepada teman-teman muslim di rumahnya di Austria. Hal ini dapat dilihat dalam kutipan berikut.

"Hanum, ini Latife, Ezra, dan Oznur," ucap Fatma memperkenalkan para model pemakai batikku. "Bagaimana Ayse? Dia tak rewel,kan?” tanya Fatma kepada 
ketiga koleganya. Hari itu sepertinya Fatma menitipkan Ayse kepada kawankawannya, sementara dirinya menghadiri kelas Jerman bersamaku.

"Jangan khawatir Fatma, dia sedang tertidur pulas di kamar.Tadi hanya rewel sebentar.Nafsu makannya tak ada hari ini, ” jawab Latife.

"Aura kekeluargaan tiba-tiba kurasakan di sana.Keempat perempuan muda itu seperti menjalin hubungan kakak-beradik yang erat.Buktinya, duplikat kunci rumah Fatma dititipkan kepada ketiga kawannya.Saat kami datang, ketiga perempuan itu sudah berada dalam rumah Fatma." (hlm. 87)

Dalam kutipan di atas dapat dilihat bahwa Fatma tidak takut menitipkan anaknya kepada teman-teman muslimnya di Austria untuk menjaga anaknya, karena kredibilitas mereka tidak diragukan lagi oleh Fatma.Dan tidak hanya itu, Fatma juga tidak segansegan menyimpan duplikat kunci rumahnya kepada mereka.

\section{Simpulan}

Berdasarkan analisis penelitian di atas dapat ditarik kesimpulan sebagai berikut:

1. Hanum Salsabiela dan Rangga Almahendra merupakan novelis yang memiliki kualitas yang mumpuni dan memiliki ciri tersendiri.Hanum dan Rangga biasa membuat novel berdasarkan skenario.Mereka mampu melakukan pendalaman materi skenario dengan memperkaya bahan penulisan serta mengubah sudut pandang penceritaan dari mata sang tokoh "aku" sehingga menghasilkan novel sebagai pelengkap kisah dalam film. Pengalamannya sebagai wartawan menjadikan Hanum begitu kaya kosa-kata sehingga menarik dan mendalam.

2. Novel 99 CdLE karya Hanum Salsabiela dan Rangga Almahendra berstrukturkan tema tentang divine (Ketuhanan). Alur yang membangun novel $99 C d L E$ adalah alur maju. Latar novel 99 CdLE adalah kelas Jerman, museum Wina, rumah Fatma, lapangan Rathaus Fan-zone, masjid Vienna Islamic Center, Paris, Cordoba \& Granada, Istambul. Tokoh utama novel $99 C d L E$ adalah Hanum Salsabiela sedangkan tokoh tambahan adalah Rangga Almahendra, Fatma Pasha, Marion Latime, Imam Hashim, Stefan, Ayse Pasa, Maarja, Khan, Latife, Ezra, Oznur, Sergio, Ranti Tobing.

3. Nilai Profetik dan pendidikan Islam humanistik dalam novel $99 C d L E$ meliputi pendidikan dan humanum, pendidikan dan humanitas, serta pendidikan dan humaniora. Namun kemudian mengingatkan kepada umat Islam agar senantiasa menyadari bahwa penciptaan manusia dimuka bumi sebagai khalifah yang memiliki tanggung jawab terhadap diri sendiri dan umat.Dan mewarisi sifat nabi berupa siddiq, amanah, tabligh, fathonah dengan menjalankan amar ma'ruf (humanisasi), nahi munkar (liberasi), serta tu'minuna billah (transendensi). Nilai profetik dan pendidikan Islam humanistik menghasilkan sebuah sistem pendidikan baru yang disebut "sistem pendidikan syumuliyyah Islam". Syumuliyyah adalah ajaran yang mencakup seluruh dimensi kehidupan manusia; dari pribadi, keluarga, masyarakat hingga negara; dari sosial, ekonomi, politik, hukum, keamanan, lingkungan, pendidikan hingga kebudayaan; dari etnis Arab hingga seluruh etnis manusia, dari kepercayaan, sistem hingga akhlak; dari Adam hingga manusia terakhir; dari sejak kita bangun tidur hingga kita tidur kembali; dari kehidupan dunia hingga kehidupan akhirat. Sistem pendidikan Syumuliyyah Islam adalah sistem pendidikan yang mengandung nilai-nilai pendidikan berupa 
pendidikan humanum, pendidikan humanitas, pendidikan humaniora, dan amar maruf (humanisasi), nahi munkar (liberasi) dan tuminunabillah (transendensi).

4. Relevansi antara sistem pendidikan syumuliyyah Islam dengan bahan ajar sastra di SMA dapat dilihat dari unsur-unsur pengembangan sikap spiritual dan sosial, menjadikan sekolah sebagai tempat belajar dan masyarakat sebagai sumber pembelajaran, mengembangkan sikap, pengetahuan, keterampilan, memberi waktu yang cukup leluasa untuk mengembangkan berbagai sikap, pengetahuan dan keterampilan yang akan bermanfaat bagi siswa.

\section{Daftar Pustaka}

Al-Ma'ruf, A.I. (2010). Kajian Stilistika Perspektif Holistik. Solo: UNS Press. . (2010). Dimensi Sosial Keagamaan Dalam Fiksi Indonesia Modern. Solo: Smart Media.

Fahruddin, M. (2008). Konsep Pendidikan Humanis dalam PerspektifAl-Qur'an. Yogyakarta: UNY. (21 November 2013).

Salsabiela, A. (2013). 99 Cahaya di Langit Eropa. Jakarta: PT Gramedia Pustaka Utama.

Kuntowijoyo. (2006). Islam sebagai Imu; Epistemologi, Metodologi dan Etika. Yogyakarta: Tiara Wacana.

Kuntowijoyo, "Menuju Ilmu Sosial Profetik", Republika (19 Agustus 1996)

Rahmanto, B. (2004). Metode Pengajaran Sastra. Yogyakarta: Kanisius.

Ratna, N.K. (2004). Teori, Metode, dan TeknikPenelitian Sastra. Yogyakarta. Pustaka Pelajar. Sayuti, (2002). Berkenalan dengan Prosa Fiksi. Yogyakarta: Gama Media. Teew, A. (1984). Sastra dan Ilmu Sastra. Jakarta: Pustaka Jaya. 